\title{
A New Lateral Growth Free Formation Technique for Titanium Silicide Using the Si/W/Ti Trilayer Structure
}

\author{
Ming-Zen Lin and Chung-Yu Wu \\ Department of Electronics Engineering and Institute of Electronics, National Chiao Tung University, \\ Hsin-Chu, Taiwan, China
}

\begin{abstract}
A Si/W/Ti trilayer structure which consists of a top insulating Si film, a middle lateral growth suppressing W film, and a bottom Ti film is proposed to form the titanium silicide. With the properly chosen thicknesses, the W/Ti films on the oxide layer can be completely converted into the $\mathrm{Ti}_{x} \mathrm{~W}_{y}$ alloy after annealing. Since the $\mathrm{Ti}_{x} \mathrm{~W}_{y}$ alloy has a higher silicidation temperature than the pure Ti film, the titanium silicide cannot be formed on top of the oxide layer and the problem of lateral growth can be solved. The thickness ranges of the W/Ti films for the $\mathrm{TiSi}_{2}$ formation without the lateral growth has been determined experimentally. Within these ranges, the obtainable sheet resistance of $\mathrm{TiSi}_{2}$ is between 0.8 and $2.5 \Omega / \square$. Moreover, the optimal annealing process is a one-step anneal at $750^{\circ} \mathrm{C}$ for $30 \mathrm{~min}$, which can be carried out in an $\mathrm{N}_{2}$ flowing open-tube furnace. The mechanism of $\mathrm{TiSi}_{2}$ formation using the trilayer structure has also been explored and verified by experimental data.
\end{abstract}

Recently the salicide (self-aligned silicide) process, which forms a silicide film in both polysilicon-gate and source/ drain regions to reduce their sheet resistance, becomes more and more attractive in VLSI technology. Generally, the refractory metal and its silicide for the salicide process have to satisfy the following requirements: (i) low silicide resistivity; (ii) easy processing; (iii) high etching selectivity between the metal and its silicide and simple etching solution; (iv) compatibility with the existing MOS process. Many candidates such as PtSi (1), $\mathrm{CoSi}_{2}$ (2), and $\mathrm{TiSi}_{2}$ (3) are now under development.

Although titanium silicide is a promising candidate for the salicide process, it has to solve two severe problems. First, the annealing ambient for titanium silicide needs a stringent control of residual $\mathrm{O}_{2}$ contaminants to avoid the oxidation of the $\mathrm{Ti}$ film, since $\mathrm{Ti}$ is a strong reducing agent. This often causes difficulties in process control. The second problem is the so-called bridging or lateral growth phenomenon which may happen between gate and source/ drain regions due to the out-diffusion of Si atoms into the $\mathrm{Ti}$ film on top of the oxide layer to form the $\mathrm{TiSi}_{2}$ bridge.

To solve the lateral growth problem, a $\mathrm{N}_{2}$ annealing process was proposed in which a TiN film is formed to stop the lateral growth of the silicide (3). In this two-step annealing process, a first anneal is performed to form the silicide at a lower temperature of $600^{\circ} \mathrm{C}$. After the etching of TiN layer, a second anneal at a higher temperature of $800^{\circ} \mathrm{C}$ is used to reduce the resistivity. During the first annealing process, the Ti film has to be exposed to the ambient. So this process still has the first problem.

In a previous work (4), we proposed a $\mathrm{Si} / \mathrm{Mo} / \mathrm{Ti}$ structure for the formation of $\mathrm{TiSi}_{2}$, which solves the problem of environmental sensitivity. In this approach, the trilayer structure is further improved by replacing the Mo layer with the $\mathrm{W}$ layer. It is found that with the suitably chosen thicknesses, the $\mathrm{Si} / \mathrm{W} / \mathrm{Ti}$ trilayer structure can be annealed in a conventional $\mathrm{N}_{2}$ flowing open-tube furnace and the lateral growth can be completely suppressed. Thus, the above-mentioned two problems can be solved. In this paper, the $\mathrm{TiSi}_{2}$ formation technology using the $\mathrm{Si} / \mathrm{W} / \mathrm{Ti}$ trilayer structure will be presented. The experimental results and the reaction mechanism will also be investigated and analyzed.

\section{Experimental}

P-type (100) wafers with a resistivity of $20-50 \Omega \cdot \mathrm{cm}$ were employed in our experiments. Two groups of samples were prepared for the silicide formation on top of the single-Si substrate and the poly-Si film. One group was oxidized to form a layer of $\mathrm{SiO}_{2}$ with a thickness of $100 \mathrm{~nm}$. Then $500 \mathrm{~nm}$ poly-Si film was deposited and doped by $\mathrm{POCl}_{3}$ to form an $\mathrm{n}^{+}$poly-Si film with a sheet resistance of $15-20 \Omega / \square$. Finally $100 \mathrm{~nm}$ polyoxide was grown and patterned. The other group was oxidized to form a $100 \mathrm{~nm}$ $\mathrm{SiO}_{2}$ layer and patterned.
After patterning, the samples were dipped in a solution of $\mathrm{HF}: \mathrm{H}_{2} \mathrm{O}=1: 50$ for 20 s to remove the native oxide on the exposed Si or poly-Si surface. Immediately, they were put into the vacuum chamber of a dual E-gun evaporator. Then the Si/W/Ti trilayer was deposited in sequence without opening the vacuum chamber.

After deposition, the samples were subjected to different annealing processes in a conventional $\mathrm{N}_{2}$ flowing opentube furnace. After annealing, some of the samples were etched in a plasma etcher to remove the top protection $\mathrm{Si}$ layer. Then they were etched in a solution of $\mathrm{H}_{2} \mathrm{O}_{2}: \mathrm{NH}_{4} \mathrm{OH}: \mathrm{H}_{2} \mathrm{O}=1: 1: 10$ to remove the middle $\mathrm{W}$ layer and the untreated $\mathrm{Ti}$ layer. Thus the bottom $\mathrm{TiSi}_{2}$ layer was uncovered for observation and measurement.

In this study, the sheet resistance of the TiSi $\mathrm{i}_{2}$ film after annealing was measured by a four-point probe. The lateral growth length after annealing was measured by a SEM and/or a microscope. AES depth profiles were generated to explore the reaction mechanism. Oxide thickness was measured by an ellipsometer before and after silicidation. And the thickness loss was then determined.

\section{Results and Discussion}

In the Si/W/Ti trilayer structure, the purpose of the top $\mathrm{Si}$ layer is to block all the contaminants from reaching the bottom Ti layer. As pointed out in our previous work (4), the top Si layer makes the silicidation process insensitive to the environment. Thus, a $\mathrm{TiSi}_{2}$ film with a good uniformity and reproducibility can be made using a conventional low cost open-tube furnace.

The second layer is the $W$ film instead of the Mo film (4). Its purpose is to form the $\mathrm{Ti}_{x} \mathrm{~W}_{3}$ alloy which has a higher silicidation temperature than the pure Ti film (5). As will be seen later, the $\mathrm{Ti}_{x} \mathrm{~W}_{y}$ alloy can efficiently suppress the lateral growth of ' $\mathrm{TiSi}_{2}$.

Optimal annealing condition.-The measured sheet resistance $R_{6}$ and lateral growth length in both poly-Si and single-Si samples with the same thickness $(100 \mathrm{~nm})$ of the top Si film and different thicknesses of the W/Ti films are listed in Tables I, II, and III where the annealing conditions are $800^{\circ} \mathrm{C}$ for $30 \mathrm{~min}, 750^{\circ} \mathrm{C}$ for $30 \mathrm{~min}$ and $750^{\circ} \mathrm{C}$ for 15 min, respectively. Typical surface topographies of the samples without and with lateral growth are shown in Fig. $1 a$ and $b$, respectively. It can be seen from Tables I-III that the silicided poly-Si shows a longer length of lateral growth and a higher sheet resistance than the single Si. For the worst-case study, all the results presented in the followings will be of the poly-Si samples only.

The resulting sheet resistance as a function of annealing temperatures is shown in Fig. 2. It can be observed that the annealing temperature must be higher than $750^{\circ} \mathrm{C}$ to get the lower sheet resistance. High-temperature anneal, however, increases the oxide thickness loss as can be seen 
Table I. The measured sheet resistance and lateral growth length of the silicided samples with different thicknesses of the W/Ti films after the anneal at $800^{\circ} \mathrm{C}$ for $15 \mathrm{~min}$

\begin{tabular}{cccccc}
\hline \multirow{2}{*}{$\begin{array}{c}\text { W/Ti thickness } \\
(\mathrm{nm} / \mathrm{nm})\end{array}$} & \multicolumn{2}{c}{$R_{\mathrm{s}}(\Omega / \square)$} & & \multicolumn{2}{c}{ Lateral growth $(\mu \mathrm{m})$} \\
\cline { 5 - 6 } & Poly & Single & & Poly & Single \\
\hline $20 / 100$ & 1.386 & 1.337 & & 1 & 0.8 \\
$100 / 100$ & 1.041 & 0.950 & & 1 & 0.8 \\
$160 / 80$ & 1.380 & 1.350 & & 1 & 0.6 \\
$80 / 80$ & 1.299 & 1.141 & & 0.8 & 0.6 \\
$120 / 60$ & 1.929 & 1.742 & & 0.8 & 0.6 \\
$60 / 60$ & 1.577 & 1.487 & & 0.6 & 0.4 \\
$80 / 40$ & 2.590 & 1.728 & 0.2 & 0 \\
$40 / 40$ & 2.410 & 1.572 & 0 & 0
\end{tabular}

Table II. The measured sheet resistance and lateral growth length of the silicided samples with different thicknesses of the W/Ti films after the anneal at $750^{\circ} \mathrm{C}$ for $30 \mathrm{~min}$

\begin{tabular}{cccccc}
\hline \multirow{2}{*}{$\begin{array}{c}\text { W/Ti thickness } \\
(\mathrm{nm} / \mathrm{nm})\end{array}$} & \multicolumn{2}{c}{$R_{\mathrm{s}}(\Omega / \square)$} & & \multicolumn{2}{c}{ Lateral growth $(\mu \mathrm{m})$} \\
\cline { 5 - 6 } & Poly & Single & & Poly & Single \\
\hline $20 / 100$ & 1.424 & 1.342 & & 1 & 0.8 \\
$100 / 100$ & 1.114 & 0.978 & & 1 & 0.8 \\
$160 / 80$ & 1.539 & 1.354 & & 1 & 0.6 \\
$80 / 80$ & 1.238 & 1.156 & & 0.8 & 0.6 \\
$120 / 60$ & 1.946 & 1.382 & & 0.8 & 0.6 \\
$60 / 60$ & 1.561 & 1.244 & & 0.6 & 0.4 \\
$80 / 40$ & 2.740 & 1.897 & & 0.2 & 0 \\
$40 / 40$ & 2.370 & 1.501 & & 0 & 0
\end{tabular}

Table III. The measured sheet resistance and lateral growth length of the silicided samples with different thicknesses of the W/Ti films after the anneal at $750^{\circ} \mathrm{C}$ for $15 \mathrm{~min}$

\begin{tabular}{clllll}
\hline \multirow{2}{*}{$\begin{array}{c}\text { W/Ti thickness } \\
(\mathrm{nn} / \mathrm{nm})\end{array}$} & \multicolumn{2}{c}{$R_{\mathrm{s}}(\Omega / \square)$} & & \multicolumn{2}{c}{ Lateral growth $(\mu \mathrm{m})$} \\
\cline { 5 - 6 } & Poly & Single & & Poly & Single \\
\hline $20 / 100$ & 1.404 & 1.395 & 1 & 0.8 \\
$100 / 100$ & 1.143 & 1.025 & 1 & 0.8 \\
$160 / 80$ & 1.501 & 1.408 & 1 & 0.6 \\
$80 / 80$ & 1.250 & 1.165 & 0.8 & 0.6 \\
$120 / 60$ & 1.924 & 1.755 & 0.8 & 0.6 \\
$60 / 60$ & 1.541 & 1.630 & 0.6 & 0.3 \\
$80 / 40$ & 2.75 & 1.962 & 0.1 & 0 \\
$40 / 40$ & 2.37 & 1.569 & 0 & 0
\end{tabular}

from the data in Table IV. So the optimum annealing temperature is $750^{\circ} \mathrm{C}$.

As can be seen from Tables II and III, nearly the same sheet resistance and lateral growth length are obtained in both anneals at $750^{\circ} \mathrm{C}$ for $30 \mathrm{~min}$ and $15 \mathrm{~min}$. However, longer annealing time enhances reproducibility. So the optimal annealing time is $30 \mathrm{~min}$ at $750^{\circ} \mathrm{C}$. All the results presented in the followings sections were taken from the samples subjected to this optimal anneal.

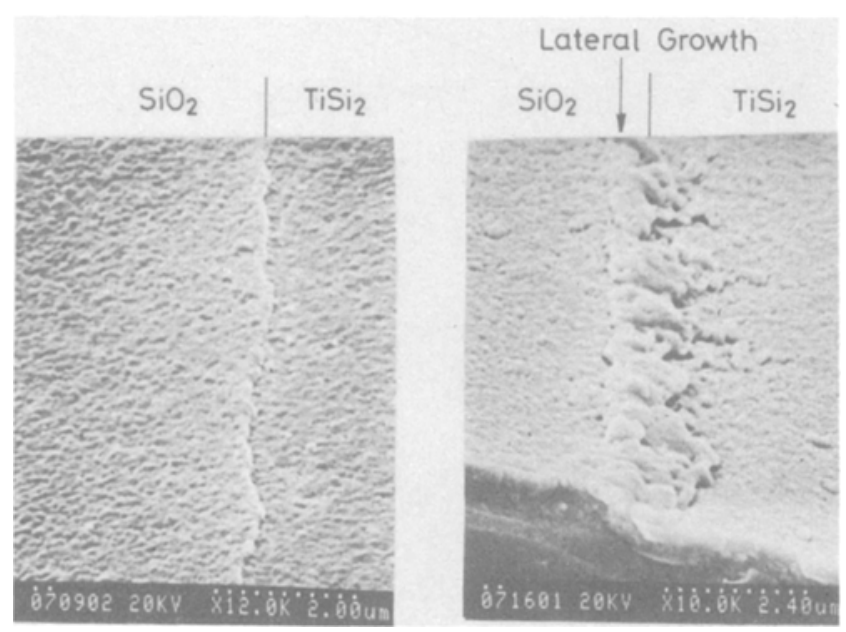

Fig. 1. SEM micrographs of the surface of the silicided samples ( $a$, left) with the $\mathrm{Si} / \mathrm{W} / \mathrm{Ti}(100 \mathrm{~nm} / 40 \mathrm{~nm} / 40 \mathrm{~nm})$ trilayer structure and annealed at $750^{\circ} \mathrm{C}$ for $30 \mathrm{~min}$; (b, right) with the Si $/ W / T i(100 \mathrm{~nm} / 100$ $\mathrm{nm} / 100 \mathrm{~nm}$ ) trilayer structure and annealed at $800^{\circ} \mathrm{C}$ for $15 \mathrm{~min}$.

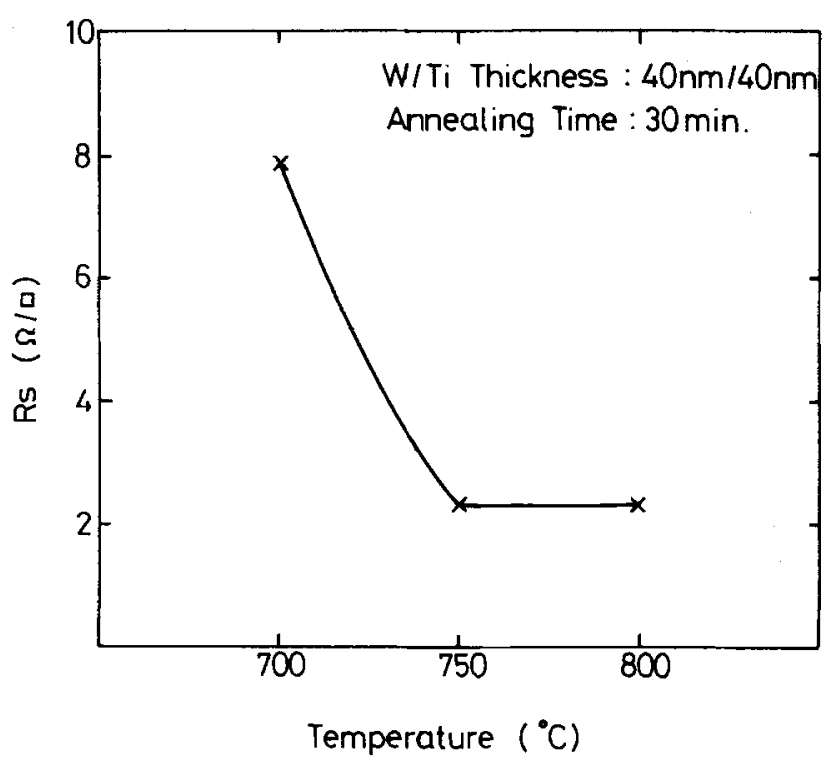

Fig. 2. Measured sheet resistance of the $\mathrm{TiSi}_{2}$ film as a function of annealing temperatures for samples with fixed thicknesses $(40 \mathrm{~nm} / 40$ $\mathrm{nm}$ ) of the W/Ti films and subjected to a $\mathbf{3 0}$ min anneal.

Si diffusion.-The AES depth profile of the as-deposited $\mathrm{Si} / \mathrm{W} / \mathrm{Ti}$ structure on the oxide layer is shown in Fig. 3. Figure $4 \mathrm{a}$ and $\mathrm{b}$ show the AES depth profiles of two $\mathrm{Si} / \mathrm{W} / \mathrm{Ti}$ trilayer structures on top of the Si substrate after the silicidation at $750^{\circ} \mathrm{C}$ for $30 \mathrm{~min}$. It can be seen from Fig. 4 that a much larger amount of Si atoms than that of $\mathrm{Ti}$ or $\mathrm{W}$ atoms have diffused into the $\mathrm{Ti} / \mathrm{W}$ layers. These $\mathrm{Si}$ atoms in the $\mathrm{W}$ film do not form tungsten silicide with $\mathrm{W}$ atoms because the annealing temperature is not high enough. The supporting evidence is that the W/Ti mixed layer after annealing is etchable in the solution of $\mathrm{H}_{2} \mathrm{O}_{2}: \mathrm{NH}_{4} \mathrm{OH}: \mathrm{H}_{2} \mathrm{O}=$ 1:1:10 which as we know is not an etchant for tungsten silicide. The AES depth profile after etching, as given in Fig. 5 , also shows no sign of tungsten silicide. Therefore, no tungsten silicide is formed in the anneal.

Figure 6 shows the AES depth profile on top of the $\mathrm{SiO}_{2}$ layer after the silicidation at $750^{\circ} \mathrm{C}$ for $30 \mathrm{~min}$. Comparing Fig. 4 with Fig. 6, we conclude that the larger amount of diffused Si atoms on top of the Si substrate as shown in Fig. 4 mainly come from the Si substrate instead of the top Si layer. Otherwise, the diffused Si atoms on top of the $\mathrm{SiO}_{2}$ layer should have nearly the same quantity. This enhanced Si diffusion along one direction might be initiated by the out-diffusion of Ti atoms into the W layer.

$T i_{x} W_{y}$ formation.-As can be seen from Fig. 4 and 6 , the $\mathrm{W}$ film has formed $\mathrm{Ti}_{x} \mathrm{~W}_{y}$ with the $\mathrm{Ti}$ film on top of both oxide layer and Si substrate. Although the AES depth profiles cannot identify exactly the composition of the $\mathrm{Ti}_{x} \mathrm{~W}_{y}$ alloy, they do show that the $\mathrm{W}$ signal is significantly overlapped by the Ti signal, which means the $\mathrm{Ti}_{x} \mathrm{~W}_{y}$ alloy is formed. From (5), we know that the $\mathrm{Ti}_{x} \mathrm{~W}_{y}$ alloy has a higher silicidation temperature than the pure Ti film. Therefore, as soon as the Ti layer on top of the $\mathrm{SiO}_{2}$ layer is completely converted into the $\mathrm{Ti}_{x} \mathrm{~W}_{y}$ alloy, any further annealing at the same temperature will have no threat of lateral growth. In our experiments, we do observe that the lateral growth is self-stopped as the annealing time is increased.

Table IV. The oxide thickness loss of the silicided samples with three different thicknesses of $\mathrm{W} / \mathrm{Ti}$ films after three different onneals

\begin{tabular}{ccccc}
\hline & \multicolumn{3}{c}{$\begin{array}{c}\text { Oxide thickness loss } \\
\text { W/Ti thickness } \\
\text { (nm/nm) }\end{array}$} \\
\cline { 2 - 2 } Annealing condition & $40 / 40$ & & $80 / 40$ & $120 / 40$ \\
\hline $800^{\circ} \mathrm{C}, 15 \mathrm{~min}$ & 35.5 & & 30.0 & 29.1 \\
$750^{\circ} \mathrm{C}, 30 \mathrm{~min}$ & 35.0 & & 32.9 & 27.9 \\
$750^{\circ} \mathrm{C}, 15 \mathrm{~min}$ & 29.9 & & 27.7 & 25.8
\end{tabular}




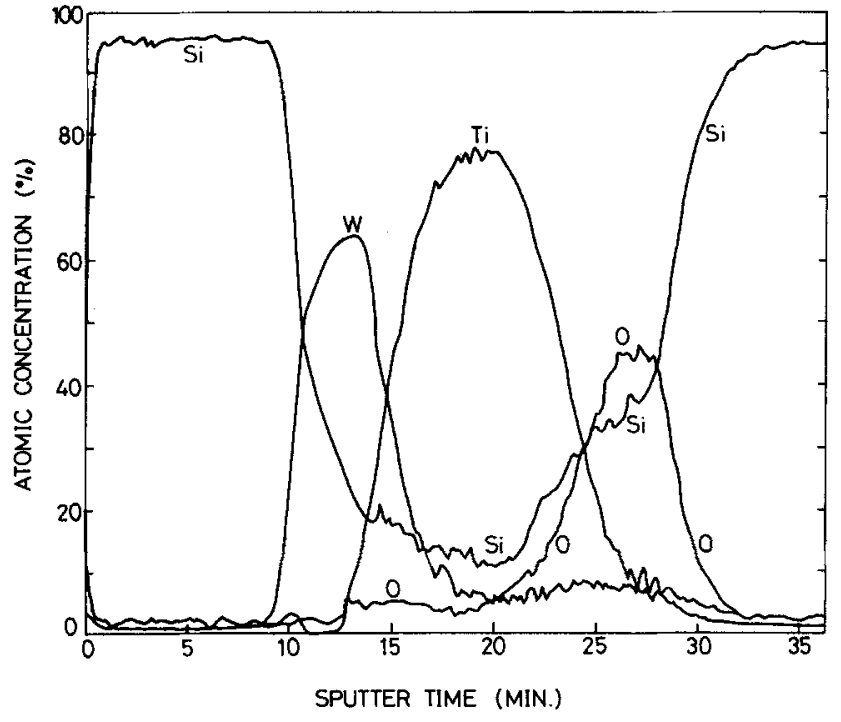

Fig. 3. AES depth profile of the as-deposited Si/W/Ti $(100 \mathrm{~nm} / 40$ $\mathrm{nm} / 40 \mathrm{~nm}$ ) trilayer structure on the oxide layer.

According to (6), $1 \mathrm{~nm}$ of Ti film can produce $2.51 \mathrm{~nm}$ of $\mathrm{TiSi}_{2}$ film and the resistivity of $\mathrm{TiSi}_{2}$ is $13-16 \mu \Omega \cdot \mathrm{cm}$ (15 $\mu \Omega \cdot \mathrm{cm}$ is used in our calculations). Using these data, we first calculate the thickness of the $\mathrm{TiSi}_{2}$ film from the measured sheet resistance and then determine the thickness of the consumed Ti film to form the TiSi $i_{2}$ film. Finally, the thickness of the consumed Ti film to form the $\mathrm{Ti}_{x} \mathrm{~W}_{y}$ film is obtained by subtracting the total thickness from the calculated thickness of the consumed $\mathrm{Ti}$ film to form the $\mathrm{TiSi}_{2}$ film. From the thickness data, the formation speeds of $\mathrm{TiSi}_{2}$ and $\mathrm{Ti}_{x} \mathrm{~W}_{y}$ can be compared.

To observe how the thickness of the $W$ film affects the formation speed of $\mathrm{Ti}_{x} \mathrm{~W}_{y}$ we calculate the thicknesses of the consumed Ti film to form the $\mathrm{TiSi}_{2}$ film and the $\mathrm{Ti}_{x} \mathrm{~W}_{y}$ film from the measured sheet resistance given in Fig. 7, where the sheet resistance as a function of the thickness of the $W$ film for a fixed thickness of the Ti film is shown. The results are given in Table $V$. It can be seen that a thicker $W$ film results in a higher formation speed of $\mathrm{Ti}_{x} \mathrm{~W}_{y}$, which even becomes higher than the formation speed of $\mathrm{TiSi}_{2}$ when the thickness of $W$ film is larger than $120 \mathrm{~nm}$. From Fig. 4 and 6 , we also see that $\mathrm{Ti}$ atoms reach the $\mathrm{Si} / \mathrm{W}$ interface even if the W film is quite thick. Moreover, as can be seen from Fig. 4b, Ti atoms are almost dissolved in the $W$ layer when a thick W film is used to form $\mathrm{TiSi}_{2}$. In other words, the diffusivity of Ti atoms in the $\mathrm{W}$ film is enhanced when a thick $W$ film is used. This explains the increase of the formation speed of the $\mathrm{Ti}_{x} \mathrm{~W}_{y}$ film due to a thick $\mathrm{W}$ film.

Due to the higher silicidation temperature, the $\mathrm{Ti}_{x} \mathrm{~W}_{3}$ alloy has a weaker ability to decompose $\mathrm{SiO}_{2}$ than the pure

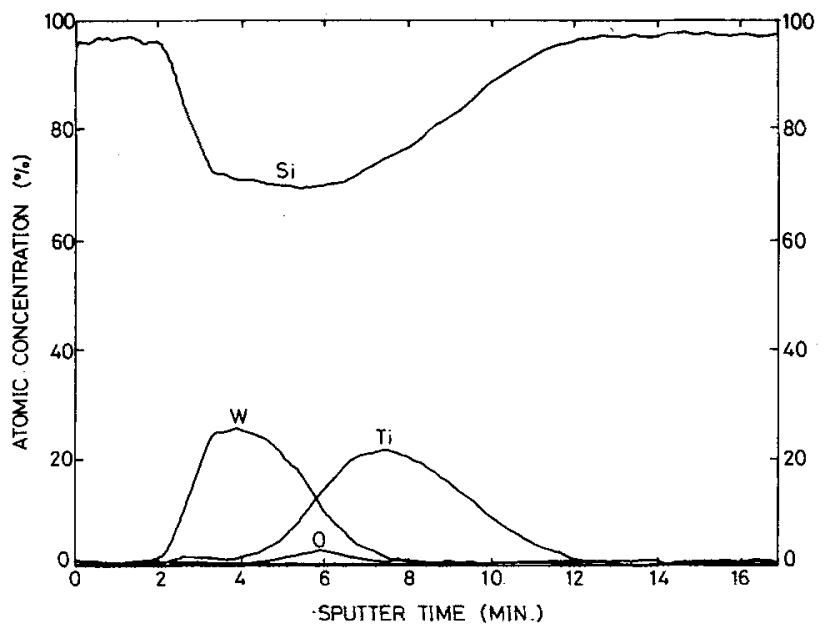

Fig. 4. AES depth profiles of the Si/W/Ti $[(a$, left $) 100 \mathrm{~nm} / 40 \mathrm{~nm} / 40 \mathrm{~nm}$; (b, right) $100 \mathrm{~nm} / 400 \mathrm{~nm} / 40 \mathrm{~nm}]$ trilayer structure on the Si substrote after silicidation ot $750^{\circ} \mathrm{C}$ for $30 \mathrm{~min}$.

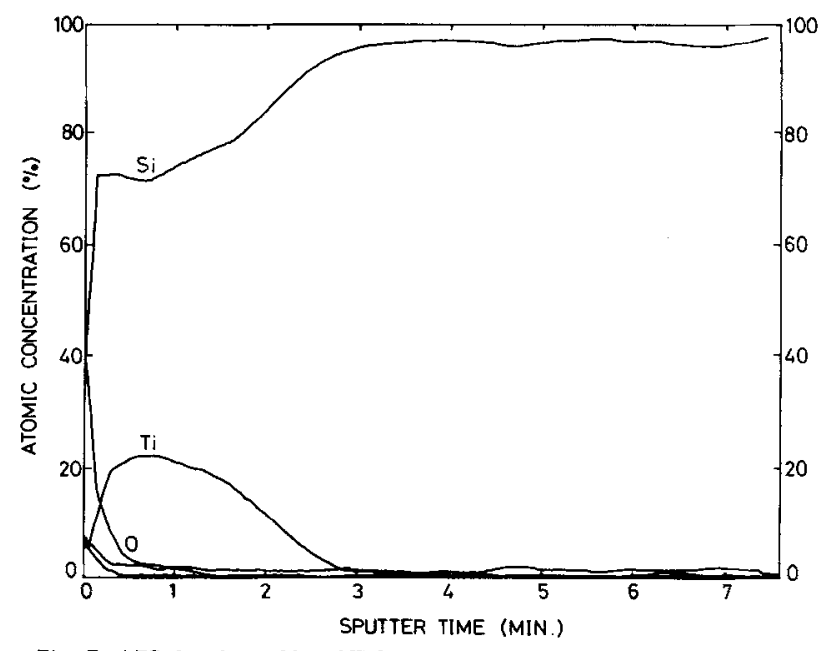

Fig. 5. AES depth profile of $\mathrm{TiSi}_{2}$ on the $\mathrm{Si}$ substrate after silicidation at $750^{\circ} \mathrm{C}$ for $30 \mathrm{~min}$ using the $\mathrm{Si} / \mathrm{W} / \mathrm{Ti}(100 \mathrm{~nm} / 40 \mathrm{~nm} / 40 \mathrm{~nm})$ trilayer structure.

Ti film at the same temperature. Thus, a thicker $\mathrm{W}$ film which generates a thicker $\mathrm{Ti}_{x} \mathrm{~W}_{y}$ film, causes less of an oxide-thickness loss. This can be verified from the data in Table IV.

To observe how the thickness of the Ti film affects the formation speed of $\mathrm{Ti}_{x} \mathrm{~W}_{y}$ the consumed thickness of the $\mathrm{Ti}$ film to form the $\mathrm{TiSi}_{2}$ film and the $\mathrm{Ti}_{x} \mathrm{~W}_{y}$ film are calculated similarly from the measured sheet resistance given in Fig. 8 , where the sheet resistance $v s$. the thickness of the Ti film for a fixed thickness of the $\mathrm{W}$ film is illustrated. The results are shown in Table VI. It can be seen that as the thickness of the Ti film increases, the consumed thickness of the Ti film to form the $\mathrm{Ti}_{x} \mathrm{~W}_{y}$ film does not increase as much as that to form the $\mathrm{TiSi}_{2}$ film. This is because a fixed thickness of the $W$ film is used so that the formation speed of $\mathrm{Ti}_{x} \mathrm{~W}_{y}$ is fixed. From the above analysis, the conclusion can be made that the formation speed of $\mathrm{Ti}_{x} \mathrm{~W}_{y}$ is not affected by the thickness of the Ti film and is slower than that of $\mathrm{TiSi}_{2}$ if the $\mathrm{W}$ film is not too thick.

Lateral growth.--As can be seen from Tables I-III and Fig. 7 that a thicker W film leads to a longer lateral growth. As mentioned above, $\mathrm{Ti}$ atoms diffuse very fast in the $\mathrm{W}$ film. After the contact of the $\mathrm{TiSi}_{2}$ and the $\mathrm{Ti}_{x} \mathrm{~W}_{y}$ layers during the formation process, the fast diffusing Ti atoms may enhance the diffusion speed of $\mathrm{Si}$ atoms in the $\mathrm{Ti}_{x} \mathrm{~W}_{y}$ film. If a thicker $\mathrm{W}$ film is used, this enhanced $\mathrm{Si}$ diffusion speed may become higher than the formation speed of $\mathrm{Ti}_{x} \mathrm{~W}_{y}$ on the oxide layer. Thus, $\mathrm{Si}$ atoms have a chance to enter the "Ti channel" on top of the oxide layer before it is the lateral growth. As can be seen from Fig. 7, the lateral growth happens when the thickness of $\mathrm{W}$ film exceeds 70 nm.

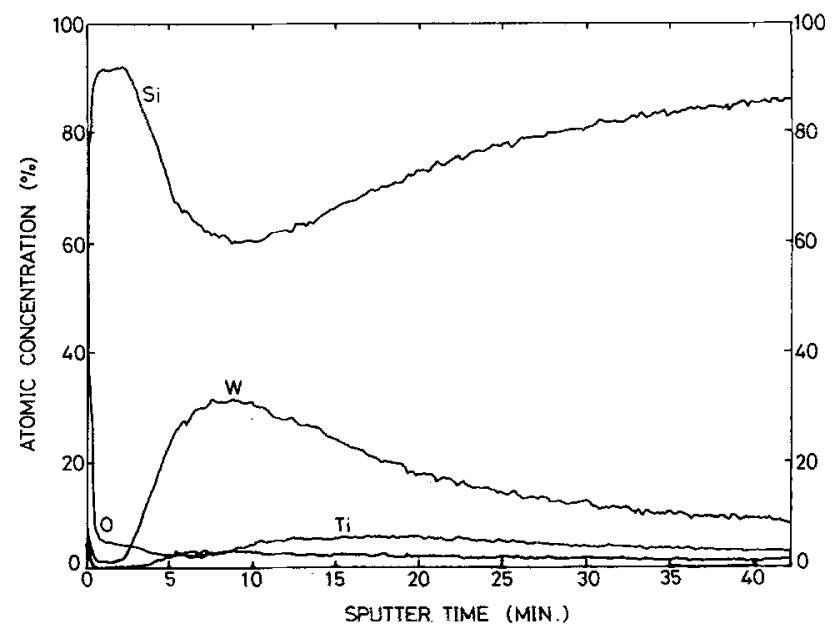
closed up by the formation of the $\mathrm{Ti}_{x} \mathrm{~W}_{y}$ alloy. This leads to 


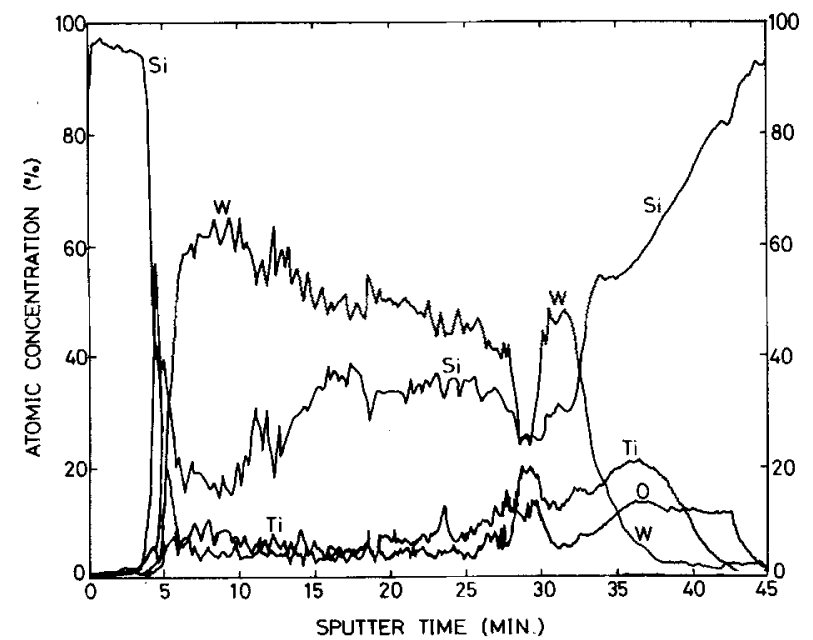

Fig. 6. AES depth profiles of the Si/W/Ti $(100 \mathrm{~nm} / 400 \mathrm{~nm} / 40 \mathrm{~nm})$ trilayer structure on the oxide layer after silicidation at $750^{\circ} \mathrm{C}$ for $30 \mathrm{~min}$.

From Fig. 7 and 8, we see that the lateral growth also happens when the thickness of the $\mathrm{W}$ film is smaller than $40 \mathrm{~nm}$ or the thickness of the Ti film is larger than $70 \mathrm{~nm}$. These data show that when the thickness ratio of the $W$ film to the Ti film is too small, lateral growth happens. This is because the $W$ film is not thick enough to convert the thick $\mathrm{Ti}$ film completely into the $\mathrm{Ti}_{x} \mathrm{~W}_{y}$ alloy on the oxide layer.

Thickness ranges of the W/Ti films for the lateral growth free process.-Based on the above discussion, the lateral growth can be avoided by using a W film with a suitable thickness not to enhance too much the diffusion of $\mathrm{Si}$ atoms. Besides, the thickness of the Ti film has to be small enough so that it can be completely converted into the $\mathrm{Ti}_{x} \mathrm{~W}_{y}$ alloy on the oxide layer. A set of samples with different thicknesses of W/Ti films were used to form $\mathrm{TiSi}_{2}$ and observe the resulting lateral growth. The results are shown in Fig. 9 where two lines can be drawn to approximately separate the region without lateral growth from that with lateral growth. The reaction in the region below the dashed line can be deemed as Case I where the Ti film is too thick. That in the region above the solid line can be considered as Case III where the $\mathrm{W}$ film is too thick. That in the region bounded by the two lines and marked by the full circles can be deemed as Case II where both Ti and $\mathrm{W}$ films are neither too thick nor too thin. There is a region corresponding to the case that the Ti film is too thin. This case is not considered because a very thin Ti film leads to a high sheet resistance which is of no practical interest.

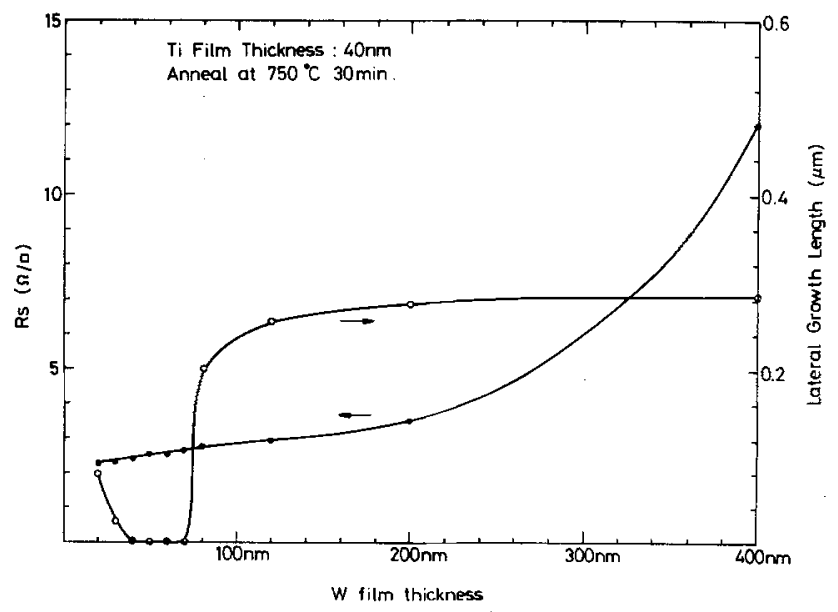

Fig. 7. Measured sheet resistance and lateral growth length as a function of thicknesses of the $W$ films ofter the silicidation at $750^{\circ} \mathrm{C}$ for $30 \mathrm{~min}$ using the $\mathrm{Si} / \mathrm{W} / \mathrm{Ti}$ trilayer structure with a fixed $\mathrm{Ti}$ film thickness of $40 \mathrm{~nm}$.

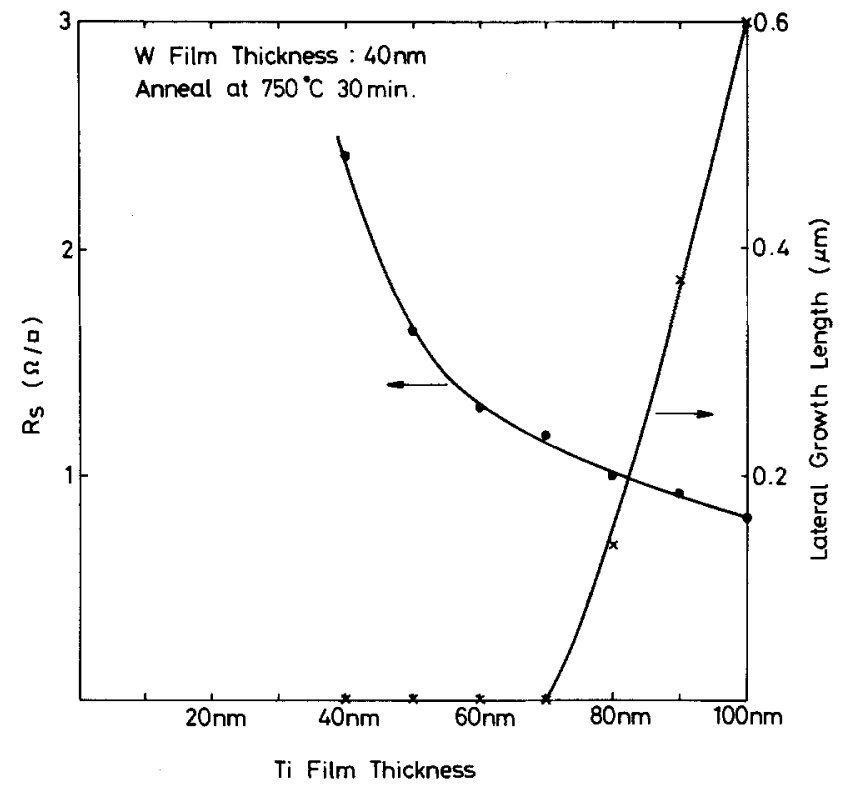

Fig. 8. Measured sheet resistance and lateral growth length as a function of thicknesses of the Ti films ofter the silicidation of $750^{\circ} \mathrm{C}$ for $30 \mathrm{~min}$ using the Si/W/Ti trilayer structure with a fixed $\mathrm{W}$ film thickness of $40 \mathrm{~nm}$.

\section{Formation Mechanisms}

From the results discussed above, the formation mechanism of $\mathrm{TiSi}_{2}$ using the $\mathrm{Si} / \mathrm{W} / \mathrm{Ti}$ trilayer structure can be figured out. Generally, the formation can be divided into two reaction steps. The first step determines the resulting sheet resistance and oxide thickness loss, while the second step determines whether the lateral growth happens or not. The mechanisms in the two-step reaction are described below.

In the first reaction step, $W$ and $T i$ atoms in the as-deposited $\mathrm{Si} / \mathrm{W} / \mathrm{Ti}$ trilayer as shown in Fig. 10a interdiffuse across the W/Ti interface to form the $\mathrm{Ti}_{x} \mathrm{~W}_{y}$ alloy. Meanwhile, Si atoms diffuse from the $\mathrm{Si}$ substrate or poly-Si gate into the $\mathrm{Ti}$ layer to form $\mathrm{TiSi}_{2}$. Thus the $\mathrm{Ti}_{x} \mathrm{~W}_{y}$ layer

Table $V$. The estimated thickness of the Ti film consumed to form $\mathrm{Ti}_{\mathrm{x}} \mathrm{W}_{\mathrm{y}}$ and $\mathrm{TiSi}_{2}$ in the $\mathrm{Si} / \mathrm{W} / \mathrm{Ti}$ trilayer structure with a fixed thickness of the $\mathrm{Ti}$ film $(40 \mathrm{~nm})$ and subjected to the anneal at $750^{\circ} \mathrm{C}$ for $30 \mathrm{~min}$

\begin{tabular}{ccc}
\hline $\begin{array}{c}\text { W thickness } \\
(\mathrm{nm})\end{array}$ & $\begin{array}{c}\text { Consumed } \\
\text { Ti thickness }_{\text {to form } \mathrm{Ti}_{x} \mathrm{~W}_{y}}\end{array}$ & $\begin{array}{c}\text { Consumed } \\
\text { Ti thickness } \\
\text { to form TiSi }\end{array}$ \\
\hline 20 & 12.21 & (nm) \\
\hline 30 & 12.84 & 27.79 \\
40 & 15.21 & 27.16 \\
50 & 16.20 & 24.79 \\
60 & 17.11 & 23.80 \\
70 & 17.95 & 22.89 \\
80 & 18.74 & 22.05 \\
120 & 20.15 & 21.26 \\
200 & 23.50 & 19.85 \\
400 & 35.02 & 16.50 \\
& & 4.98
\end{tabular}

Table VI. The estimated thickness of the Ti film consumed to form $\mathrm{Ti}_{x} \mathrm{~W}_{\mathrm{y}}$ and $\mathrm{TiSi}_{2}$ in the $\mathrm{Si} / \mathrm{W} / \mathrm{Ti}$ trilayer structure with a fixed thickness of the $W$ film $(40 \mathrm{~nm})$ and subjected to the anneal at $750^{\circ} \mathrm{C}$ for $30 \mathrm{~min}$

\begin{tabular}{ccc}
$\begin{array}{c}\mathrm{Ti} \\
\text { thickness } \\
(\mathrm{nm})\end{array}$ & $\begin{array}{c}\text { Consumed } \\
\text { Ti thickness } \\
\text { to form Ti } \mathrm{W}_{y} \\
(\mathrm{~nm})\end{array}$ & $\begin{array}{c}\text { Consumed } \\
\text { Ti thicknes } \\
\text { to form TiSi } \\
(\mathrm{nm})\end{array}$ \\
\hline 40 & 15.21 & 24.79 \\
50 & 13.57 & 36.43 \\
60 & 14.04 & 45.96 \\
70 & 18.49 & 51.51 \\
80 & 20.24 & 59.76 \\
90 & 23.60 & 66.40 \\
100 & 25.30 & 74.70
\end{tabular}




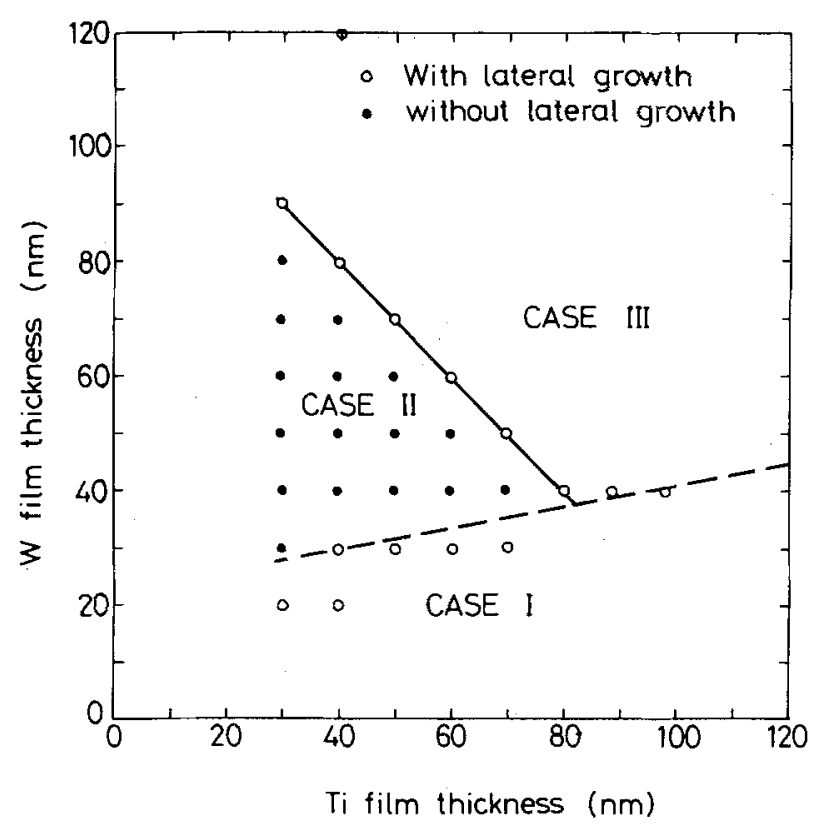

Fig. 9. Measured thickness range of the $W / T i$ films of the silicided samples with and without lateral growth. In the figure three different reaction cases are indicated.

grows downward while the $\mathrm{TiSi}_{2}$ layer grows upward. Finally, their boundaries meet together as shown in Fig. 10b. The formation speed of $\mathrm{Ti}_{x} \mathrm{~W}_{y}$ is slower than that of $\mathrm{TiSi}_{2}$ if the W film is not too thick, as may be seen from the data of Table V. On the other hand, if the W film is thicker, the formation speed of $\mathrm{Ti}_{x} \mathrm{~W}_{y}$ becomes higher than that of $\mathrm{TiSi}_{2}$. Thus more $\mathrm{Ti}$ atoms are dissolved in the $\mathrm{W}$ layer and less $\mathrm{TiSi}_{2}$ is formed. This leads to a higher sheet resistance and a less oxide thickness loss.

In the second reaction step, $\mathrm{Ti}$ atoms in the $\mathrm{Ti}_{x} \mathrm{~W}_{y}$ layer continue to diffuse into the $\mathrm{W}$ layer to form the $\mathrm{Ti}_{x} \mathrm{~W}_{y}$ alloy. The diffusion speed of $T i$ atoms in the $W$ film is so fast that they diffuse across the whole $W$ film and reach the $\mathrm{Si} / \mathrm{W}$ interface. In addition, the thicker the $\mathrm{W}$ film is, the faster this diffusion speed is. From the analyses of experimental results, we believe that the diffusion of $\mathrm{Ti}$ atoms in the $\mathrm{W}$ layer also greatly enhances the diffusion of Si atoms from the $\mathrm{TiSi}_{2}$ and the $\mathrm{Ti}_{x} \mathrm{~W}_{y}$ layers into the $\mathrm{W}$ layer. Without the aid of the diffusion of Ti atoms, only a few Si atoms in the top Si layer can diffuse into the $W$ layer in a direction opposite to that of the Ti diffusion. Thus, the top Si layer does not disturb the formation of $\mathrm{TiSi}_{2}$.

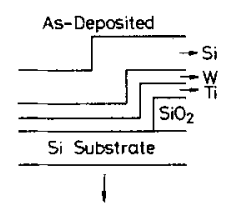

(a)

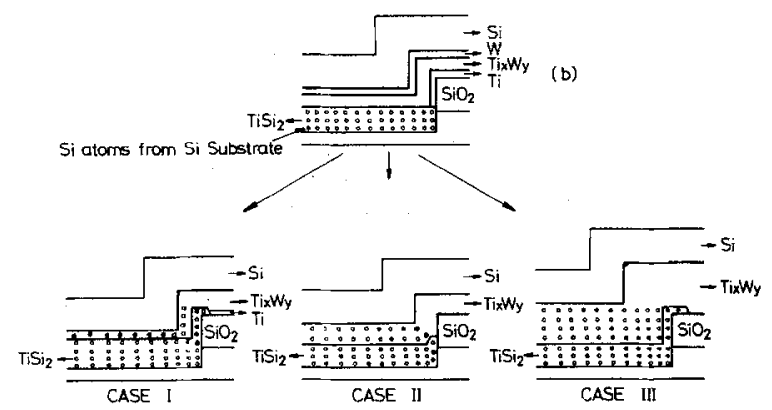

Fig. 10. Cross-section views of (a) the as-deposited Si/W/Ti trilayer structure on the Si substrate; (b) the structure after the first reaction step in forming the $\mathrm{TiSi}_{2} ;$ (c) the structure after the second reaction step in forming the $\mathrm{TiSi}_{2}$, which has three different cases: I) the Ti film is too thick; II) both Ti and W films are not too thick; III) the W film is too thick.
On top of the oxide layer, the $\mathrm{Ti}$ and the $\mathrm{W}$ atoms continue to interdiffuse to form $\mathrm{Ti}_{x} \mathrm{~W}_{y}$. The formation speed of $\mathrm{Ti}_{x} \mathrm{~W}_{y}$ as well as the thickness of the $\mathrm{Ti}$ film determines whether the residual "Ti channel" on top of the oxide layer can be closed up in time or not. Depending on the chosen thicknesses of the W/Ti films, the second reaction step can be further divided into three different cases as shown in Fig. 9. Their corresponding cross-sectional views are given in Fig. 10c.

Case I-If the Ti film is too thick, the formation speed of $\mathrm{Ti}_{x} \mathrm{~W}_{y}$ becomes much slower than that of $\mathrm{TiSi}_{2}$ as may be seen in Table VI. Thus more $\mathrm{TiSi}_{2}$ is formed and the height of the $\mathrm{TiSi}_{2}$ layer is closer to that of the $\mathrm{SiO}_{2}$ wall. So the required distance for the lateral growth of $\mathrm{TiSi}_{2}$ on top of the oxide layer is reduced. Due to these two effects, the "Ti channel" cannot be closed up in time. Thus Si atoms diffuse along the "Ti channel" and $\mathrm{TiSi}_{2}$ grows laterally on top of the oxide layer.

Case II-If both Ti and W films are not too thick, the diffusivity of Si atoms is not too much enhanced and the formation speed of $\mathrm{Ti}_{x} \mathrm{~W}_{y}$ is not cut down. Meanwhile the thickness of the $\mathrm{Ti}$ film is smaller than that in the Case I. The $\mathrm{Ti}_{x} \mathrm{~W}_{y}$ alloy, therefore, can close up the residual "Ti channel" before $\mathrm{Si}$ atoms could diffuse in. So the lateral growth can be completely suppressed.

Case III-If the W film is too thick, the diffusivity of $\mathrm{Si}$ atoms in the second reaction step is enhanced to such an extent that it becomes faster than the formation speed of $\mathrm{Ti}_{x} \mathrm{~W}_{y}$ on top of the oxide layer. In this case, the residual "Ti channel" cannot be closed up in time to stop the lateral growth. When a thicker Ti film is used, a shorter distance is required for $\mathrm{TiSi}_{2}$ to climb to the top of the oxide layer as mentioned in case I. A thinner W film thus can enhance enough diffusivity of Si atoms to cause the lateral growth. This leads to the negative slope of the line separating the regions of case II and case III.

\section{Conclusions}

In this study, we have shown that using the Si/W/Ti trilayer structure with suitable thicknesses of the W/Ti films, the lateral growth problem in the titanium silicide formation can be overcome. The formation mechanism of such a lateral growth free silicidation technology have also been explored. According to the mechanism, the main factors associated with the suppression of the lateral growth are: (i) $\mathrm{W}$ atoms react with $\mathrm{Ti}$ atoms to form the $\mathrm{Ti}_{x} \mathrm{~W}_{y}$ alloy, which has a higher silicidation temperature than the pure Ti film; (ii) the thickness of the W film is chosen so that the W film can completely convert the Ti film on top of the oxide layer into the $\mathrm{Ti}_{x} \mathrm{~W}_{y}$ alloy without enhancing too much the out-diffusion of Si atoms. It is shown that a low resistivity $\mathrm{TiSi}_{2}$ layer without the lateral growth can be formed through an anneal at $750^{\circ} \mathrm{C}$ for $30 \mathrm{~min}$ in an $\mathrm{N}_{2}$ flowing open-tube furnace which needs no stringent environmental control. And it is a simple one-step annealing process instead of the conventional two-step annealing process. It is expected that the developed silicidation process can be easily incorporated into various VLSI technologies to promote the device and circuit performance.

\section{Acknowledgments}

The authors would like to thank the National Science Council for the support of this research under Grant no. NSC76-0404-E009-12, the Semiconductor Research Center, National Chiao Tung University, and the United Microelectronics Corporation for preparing samples and generating SEM micrographs, and the SAM Laboratory of the Precious Instruments Center, National Tsing Hua University for doing the AES analyses.

Manuscript submitted Oct. 19, 1987; revised manuscript received about Feb. 1, 1988.

National Chiao Tung University assisted in meeting the publication costs of this article.

\section{REFERENCES}

1. T. Shibata, K. Hieda, M. Sato, M. Konaka, R. L. M. Dang, and H. Iizuka, IEEE J. Solid State Circuits, 17, 161 (1982). 
2. L. Van den hove, R. Wolters, K. Maex, R. De Keersmaecker, and G. Declerck, IEEE Trans. Electron Devices, 34, 554 (1987).

3. M. E. Alperin, T. C. Holloway, R. A. Haken, C. D. Gosmeyer, R. V. Karnaugh, and W. D. Parmantie, IEEE J. Solid State Circuits, 20, 61 (1985).
4. M.-Z. Lin, Y.-C. Yu, and C.-Y. Wu, This Journal, 133, 2386 (1986).

5. S. E. Babcock and K. N. Tu, J. Appl. Phys., 53, 6898 (1982).

6. S. P. Murarka, "Silicides for VLSI Applications," Academic Press, Inc., New York (1983).

\title{
Advanced KrF Excimer Laser Stepper for Half Micron Lithography
}

\author{
K. Ogawa, M. Sasago, M. Endo, H. Nakagawa, Y. Tani, and T. Ishihara \\ Matsushita Electric Industrial Company, Limited, Semiconductor Research Center, Moriguchi, Osaka, 570 Japan
}

\section{ABSTRACT}

An excimer laser stepper operating at $248.4 \mathrm{~nm}$ was developed for use in $0.5 \mu \mathrm{m}$ pattern fabrication. The excimer laser stepper consists of a new compact $\mathrm{KrF}$ excimer laser, whose oscillation spectrum has been line-narrowed (FWHM 0.007 $\mathrm{nm}$ ), and a monochromatic fused silica lens. The 5 times projection lens has a field size of $15 \times 15 \mathrm{~mm}^{2}$ and a numerical aperture (NA) of 0.36 . A pattern exposure of $0.5 \mu \mathrm{m}$ features without speckle is possible using this apparatus, and resolution of $0.4 \mu \mathrm{m}$ line and space patterns were obtained by using commercially available deep UV resist. A high throughput, equivalent to that of a conventional stepper, is further obtained. Since it is expected that the mask alignment accuracy of $\pm 0.1 \mu \mathrm{m}$ will be obtained, and some suitable resist for the excimer laser stepper will be developed in the near future, excimer laser lithography will become an important technique for the fabrication of semiconductor devices with $0.5 \mu \mathrm{m}$ design rules such as 16 Mbit DRAM's.

In recent years, as semiconductor device production technology has progressed, photolithography has approached the $0.5 \mu \mathrm{m}$ level which is said to be the limit when using UV light. In order to find a way to exceed this limit, conventional projection exposure apparatus of high NA and short wave length type such as an i-line stepper, an $\mathrm{x}$-ray exposure apparatus, a direct writing electron beam (EB) exposure apparatus, and an excimer laser exposure apparatus (1-3) are all being worked on at present.

It seems, however, that it will be difficult to exceed this limit with any of the first three techniques. Development of a high NA-type stepper which uses a conventional ultrahigh pressure mercury lamp as a light source, is difficult due to the difficulty involved in designing a lens for large area exposure, even if an $\mathrm{i}$-line of an ultrahigh pressure mercury lamp is used. The EB exposure technique, which is suitable for fabrication of a fine pattern, has poor throughput. With the x-ray exposure technique, it is difficult both to produce masks for exposure and to obtain a high sensitivity resist which can be used with the low power sources available at present. With the excimer laser exposure technique, however, a high resolution exceeding this $0.5 \mu \mathrm{m}$ limit seems possible if peripherals from conventional steppers are used by replacing the light source and the optical system.

An important feature of the excimer laser is that light of short wavelength and high power, with extremely small spectrum dispersion, is obtained easily. For example, in a conventional $\mathrm{KrF}$ laser, the spectrum dispersion of the oscillated light is $248.4 \pm 0.3 \mathrm{~nm}$, and this spectrum dispersion can be made even smaller. Accordingly, lens design is substantially simplified by using the excimer as a light source for exposure, and production of a lens for large area exposure becomes possible. The theoretical resolution for $\mathrm{KrF}$ lasers is about $0.3 \mu \mathrm{m}$. In mask production, conventional techniques can be used except that the mask material must be quartz. Furthermore, excimer laser stepper throughput is as good as that of a conventional stepper. Accordingly, the excimer laser exposure technique seems to be the most promising, as long as practicality is considered.

Many attempts to apply the excimer laser to semiconductor lithography have already beei. reported. For example, there are two reports on the contact exposure method; one using a XeCl laser (308 $\mathrm{nm}$ ) by Jain et al. (4) and the other using a $\mathrm{F}_{2}$ laser $(157 \mathrm{~nm})$ by Craighead et al. (5). They examined the possibility of excimer exposure as a new op- tical technique in detail, but the contact exposure method is out of consideration because the contact easily causes damage to the mask. There are also two examples of projection exposure using a laser source; one using a $\mathrm{XeCl}$ laser and Ofner-type reflection optics (6) which is conventionally adapted to a mirror projection exposure apparatus by Jain et al. (7), and the other using an ArF laser (193 nm) and Schwartzchild-type reflection object mirror by Erlich et al. (8). It is true that a projection stepper using a mirror system is easily constructed because Al-plated mirrors are easily obtained without chromatic aberration revision. A large exposure area, however, cannot be obtained. Therefore, a stepper using a refractive optical lens is ideal to enable one to obtain a large exposure area.

There are two types of steppers using excimer lasers as an exposure light source (excimer laser stepper). One is a type in which the excimer laser replaces the mercury lamp used as an exposure light source in the conventional UV stepper. The reduction lens is made by the same chromatic aberration revision method as in the conventional stepper (achromatic lens). There are steppers of this type using a $\mathrm{KrF}$ excimer laser and microscope objective for ultraviolet ray by Dubroeucq et al. (1). The other type of excimer laser stepper uses laser light of very narrow dispersion (almost monochromatic light) as an exposure source and a reduction lens of a monochrome design (chromatic lens). An example of this type is one designed by Pol et al. (2) in which a narrowed band $\mathrm{KrF}$ laser and a monochromatic lens are used.

The first type of excimer stepper is free from controlling spectrum dispersion of laser light, but the lens design for a large area exposure may be difficult. The possibility of obtaining large area exposures of $15 \times 15 \mathrm{~mm}^{2}$, which is required to make memory devices (for example $16 \mathrm{Mbit}$ DRAM's, etc.), is extremely small. This paper describes the development and evaluation of an excimer laser stepper using a monochromatic refraction lens for large area exposure.

\section{Excimer Laser Stepper System}

Excimer lasers often used as exposure light sources are $\mathrm{XeCl}, \mathrm{KrF}$, and $\mathrm{ArF}$, as shown in Table I. ArF laser light produces some damage to devices as well as surface traps which cause the decrease of lifetime of minority carriers. Also, the lens material is largely restricted, and developing a satisfactory resist material is difficult. For $\mathrm{XeCl}$ laser light, appropriate lens material and resists are readily 